\title{
Age-related Changes of $\mathbf{n}-3$ and $\mathbf{n}-6$ Polyunsaturated Fatty Acids in the Anterior Cingulate Cortex of Individuals with Major Depressive Disorder
}

\author{
Sarah M. Conklin ${ }^{a, b}$, Caroline Runyan ${ }^{c}$, Sherry Leonard ${ }^{d}$, Ravinder D. Reddy ${ }^{a, e}$, Matthew F. \\ Muldoon $^{a, f}$, and Jeffrey K. Yao ${ }^{a, e, g,{ }^{*}}$ \\ a Medical Research Service, VA Pittsburgh Healthcare System, Pittsburgh, PA, USA \\ ${ }^{b}$ Neuroscience Program and Department of Psychology, Allegheny College, Meadville, PA, USA \\ c Massachusetts Institute of Technology, Cambridge, MA, USA \\ d Denver VA Medical Center, and Departments of Psychiatry and Pharmacology, University of \\ Colorado Health Sciences Center, Denver, CO, USA \\ e Department of Psychiatry, University of Pittsburgh Medical Center, Pittsburgh, PA, USA \\ ${ }^{f}$ Center for Clinical Pharmacology, University of Pittsburgh, School of Medicine, Pittsburgh, PA, \\ USA \\ 9 Department of Pharmaceutical Sciences, University of Pittsburgh School of Pharmacy, Pittsburgh, \\ PA, USA
}

\section{Abstract}

Accumulating evidence finds a relative deficiency of peripheral membrane fatty acids in persons with affective disorders such as unipolar and bipolar depression. Here we sought to investigate whether postmortem brain fatty acids within the anterior cingulate cortex (BA 24) varied according to the presence of major depression at the time of death. Using capillary gas chromatography we measured fatty acids in a depressed group $(\mathrm{n}=12)$, and in a control group without lifetime history of psychiatric diagnosis $(n=14)$. Compared to the control group, the depressed group showed significantly lower concentrations of numerous saturated and polyunsaturated fatty acids including both the n-3 and n-6 fatty acids. Additionally, significant correlations between age at death and precursor (or metabolites) in the n-3 fatty acid pathway were demonstrated in the depressed group but not in control subjects. In the $n-6$ fatty acid family, the ratio of 20:3(n-6)/18:2(n-6) was higher in patients than in control groups, whereas the ratio of 20:4(n-6)/20:3(n-6) was relatively decreased in patients. Lastly, a significant negative correlation between age and the ratio of 20:4(n-6) to 22:6 (n-3) was found in patients, but not in controls. Taken together, decreases in 22:6(n-3) may be caused, at least in part, by the diminished formation of 20:5(n-3), which is derived from 20:4(n-3) through a $\Delta 5$ desaturase reaction. The present findings from postmortem brain tissue raise the possibility that an increased ratio of 20:4(n-6) to 22:6(n-3) may provide us with a biomarker for depression. Future research should further investigate these relationships.

\footnotetext{
"Corresponding author: Tel: +1 412954 5787; fax: +1 412954 5786, jkyao@ pitt.edu.
}

Publisher's Disclaimer: This is a PDF file of an unedited manuscript that has been accepted for publication. As a service to our customers we are providing this early version of the manuscript. The manuscript will undergo copyediting, typesetting, and review of the resulting proof before it is published in its final citable form. Please note that during the production process errors may be discovered which could affect the content, and all legal disclaimers that apply to the journal pertain. 


\section{Keywords}

Depression; anterior cingulate cortex; postmortem; n-6 fatty acids; arachidonic acid; n-3 fatty acids; eicosapentaenoic acid; docosahexaenoic acid; age

\section{Introduction}

Fatty acids are essential components of membrane phospholipids and are highly enriched in the central nervous system (CNS). The long-chain polyunsaturated n-3 fatty acids, eicosapentaenate (EPA) and docosahexaenate (DHA), are known to be crucial for growth and development of the CNS [1,2]. Since the functioning of cellular membranes is dependent on morphological characteristics, even minute differences in fatty acid composition can influence receptor binding, neurotransmission, signal transduction, and hormone synthesis [3]. Humans are unable to synthesize the essential n-3 18-carbon fatty acids de novo and so must obtain these fats from dietary sources. Specific plant based oils provide the 18-carbon fatty acids while marine plants and seafood provide the longer chain fatty acids such as EPA and DHA. The 18carbon n-6 fatty acid, linoleic acid, is similarly essential; however characteristics of modernday diets provide for disproportionate intakes of this fatty acid family, predominantly from corn and soy oils [4,5]. Inverse correlations have been reported between deficient consumption of the n-3 fatty acids and prevalence of affective disorders at the population level [6-8]. At the same time, it has been hypothesized that dramatic increases in the consumption of $\mathrm{n}-6$ fatty acids may be related to population-wide increases in obesity, cardiovascular disease, inflammatory disorders, and depression [3].

Cross-sectional studies of humans reveal broad roles of fatty acids in mood and affect regulation, memory, learning and brain development. For example, individuals with affective disorders, such as unipolar and bipolar depression, show a number of fatty acid deficiencies in peripheral tissues including red blood cells, serum, plasma and adipose tissue [9-13]. Further, increased ratios of arachidonic acid (AA) to EPA have also been observed in the serum and RBC lipids of patients with affective disorders and levels correlate with illness severity [14]. Supplementation with the long-chain n-3 PUFAs have been shown to improve mood in controlled trials in patients with unipolar and bipolar depression [12,15-19]. A meta-analysis of prospective trials with the long-chain n-3 fatty acids concluded that fatty acid supplementation significantly reduced symptom severity in bipolar and unipolar depression [1] although negative trials have been reported (20). Lastly, these associations extend to the variability of depressive symptomatology such that low serum levels of n-3 fatty acids have also been associated with mild to moderate depressive symptomatology in healthy adults [21].

As reviewed above, most studies relating fatty acids to psychopathology and/or normative variability of mood and behavior have been conducted in peripheral tissues or with dietary consumption data. It is generally believed that circulating levels of these fatty acids provide a nutrient supply to the CNS, thereby directly influencing the dynamic nature of neuronal membrane function. Only Lalovic and colleagues [22] and McNamara et al [23,24] have conducted postmortem fatty acid analyses on brain tissue. Lalovic and her colleagues [22] investigated the postmortem fatty acid content of orbitofrontal and ventral prefrontal cortex. They assessed 49 different fatty acids among three groups, including suicide completers, suicide completers with major depressive disorder (MDD) and a non-psychiatric control group, and found no significant between-group differences in these brain areas. However, McNamara et al [23] reported that cortical DHA composition (from Brodmann Area 10) was reduced by $22 \%$ in a small sample of deceased patients with MDD compared to non-psychiatric controls. In the current study, we investigated the brain fatty acid profile in postmortem anterior cingulate 
cortex (ACC; Brodmann area 24), a brain region showing consistent morphological and metabolic differences in MDD [25], in two groups: one with and one without a diagnosis of MDD at the time of death.

The ACC has dense interconnections with subcortical limbic areas and the prefrontal cortex and, thus, plays an important role in attention [26], motivation [27] and the regulation of emotional behavior [28]. A convergence of findings implicates the ACC in a number of psychiatric conditions including unipolar and bipolar depression [28], anxiety disorders [29], and phobias [30]. Surgical lesions of the ACC have successfully treated severe and unresponsive anxiety and mood disorders [31]. Interestingly, other research suggests that ACC activity and morphology correlates with autonomic reactivity to psychological stressors [32]. Lastly, pre-treatment metabolic [33] and electrical activity [34] of the ACC predicted treatment responsiveness in unipolar depressed patients. Since aberrant morphological, electrical and metabolic characteristics of the ACC predict psychiatric disease, and appear to be related to the pathogenesis of MDD, we chose to conduct our analyses on this prominent node of the cortico-limbic circuitry implicated in emotion regulation.

We hypothesized that the associations previously observed in peripheral tissues [35], and in preliminary structural brain imaging $[36]$ and postmortem studies $[23,24]$ would similarly vary by diagnostic group and extend to fatty acid contents within the ACC.

\section{Methods and Materials \\ Postmortem Brain Tissues}

Tissue was collected at autopsy, following donation by the family, from several sources in the Denver area: University Hospital, Denver Veterans Administration Hospital, Arapahoe and Denver County Coroners, and the Mile High Tissue Bank. Brains with neurodegenerative diseases were excluded from the present study.

At autopsy, brains were weighed and examined for gross pathology. Each brain was divided sagittally and one hemisphere, selected randomly, was preserved in formalin for neuropathological analysis at the macroscopic and microscopic level. Microscopic evaluations included standard Bielchowsky silver stain on multiple cerebral areas to rule out abnormal neuropathology, such as plaques and tangles, associated with Alzheimer's Disease and other conditions. Subjects with positive neuritic findings or ambiguous neuropathology reports were excluded from the current study. The hemisphere that was not subjected to neuropathological analysis was sliced coronally into $1 \mathrm{~cm}$ slices, from which multiple regions were dissected in 1-gram blocks, frozen in dry ice snow, and packaged for storage at $-80^{\circ} \mathrm{C}$ [37]. In the present study, Brodmann's Area 24 (BA 24), the anterior mid-cingulate region, was used for fatty acid analyses. All samples were shipped on dry ice by Federal Express to Dr. Yao's laboratory at the Highland Drive VA Pittsburgh Healthcare System.

An extensive review of hospital, autopsy, and neuropathology reports were conducted to determine premorbid agonal and postmortem conditions for each subject. Based upon this information, an agonal state score was assigned following the four-point rating scale described by Hardy et al. [38]. These four categories included 1) violent and fast death, almost always of unnatural causes such as shootings (accidental, homicidal, or suicide) or blunt force trauma; 2) fast death of natural causes, such as the sudden, unexpected deaths of individuals who had appeared reasonably healthy (the most common cause of death in this group was myocardial infarction); 3) intermediate death, usually unexpected, even though the patient was ill prior to death; and 4) slow death, occurring after a long illness (the majority of these patients died of cancer or chronic pulmonary disease). 


\section{Psychiatric Diagnosis and Non-psychiatric Control Group}

Psychiatric illness status was determined independently by two board-certified psychiatrists from medical records and structured family interviews. Two subjects' data from the MDD/ BPD group were excluded from analyses due to missing data and one control subjects data was excluded from analyses due to abnormal values for a number of fatty acids. The final sample consisted of 14 participants in the control group and 12 in the MDD group. Three of the twelve subjects in the MDD group had comorbid Bipolar Disorder (BPD) and were determined to be depressed at the time of death; thus, the group is labeled MDD/BPD. Control subjects were also evaluated and, had no evidence of psychiatric illness.

Additional parameters, such as age, sex, ethnicity, medication history, psychiatric illness status, cigarette smoking history and alcohol use, were evaluated through hospital, autopsy, and neuropathology reports. Family members and physicians were also interviewed to detail the smoking and alcohol history of the subject. A comparison of participant demographic, cause of death and brain collection variables is presented in Table 1 .

\section{Quantitative Determination of Brain Fatty Acid Composition}

Approximately $0.2 \mathrm{~g}$ of each brain sample was first weighed and lyophilized before the dry weight was taken. The method used to extract brain lipids and determine fatty acid composition by capillary gas chromatography was essentially the same as described by Yao et al. [39,40]. Diheptadecanoyl lecithin (Matraya, Inc.) was used as an internal standard. In brief, the fatty acid methyl esters were prepared from lipid extracts of brain BA-24 area and analyzed on a Hewlett-Packard capillary gas chromatograph, Model 5890 Series II, equipped with a hydrogen flame ionization detector. A 30 meter, fused silica SP-2380 column, with an inner diameter of $0.32 \mathrm{~mm}$ and a $0.20 \mu \mathrm{m}$ film thickness (Suppelco, Inc.) was used. Each sample was run under a splitless injection mode with hydrogen as the carrier gas $(30 \mathrm{~mL} / \mathrm{min}$.) and with an inlet pressure of 6.5 psi. Oven temperature was programmed under three stages: Stage 1 - from 50 to $150^{\circ} \mathrm{C}$ at a rate of $25^{\circ} \mathrm{C} / \mathrm{min}$. at $255^{\circ} \mathrm{C}$. More than 30 fatty acid methyl esters can be separated under this condition. Peaks on the chromatograms were identified by comparing the retention times with those of standard mixtures (Supleco, Inc.) and were calculated by an Agilent ChemStation, Rev A.09.03, using an internal standard mode. Mean fatty acid composition was determined as an absolute concentration $(\mathrm{nmol} / \mathrm{ml})$ and as a weight percentage.

\section{Edema Measurement in the Anterior Cingulate Cortex Samples}

Cerebral edema is commonly seen in a variety of pathological processes in the brain. To determine the water content in the ACC samples, we measured both fresh and dry weight of each sample to calculate the percentage of swelling (edema) or of shrinkage using the formula of Elliott and Jasper [41]. Based on these calculations there were no significant differences between MDD/BPD and the control group (data not shown).

\section{Effect of Postmortem Interval (PMI) on Cerebral Cortex Fatty Acids}

The stability of postmortem cerebral cortex fatty acids was investigated by Carver et al. [42]. Their data indicated that the fatty acid composition of frontal cerebral cortex remained stable for up to 25 hours after death. Significant hydrolysis of fatty acids from lipid moieties occurs during the postmortem period. In the present study, the PMI from both control and MDD/BPD groups was $<25$ hours (Table 1 ). Samples were stored at $-70^{\circ} \mathrm{C}$ and were not previously thawed prior to the present study. Thus, it is reasonably concluded that the present findings are not due to different rates of lipid hydrolysis resulting from PMI or storage condition. 


\section{Statistical Analyses}

The distributions for all variables were examined using the Kolmogorov-Smirmov test which quantifies the discrepancy between data distribution and an ideal Gaussian distribution. The frequency distributions of race, alcohol use, sex and smoking status were compared using $\mathrm{X}^{2}$ analysis. Group means for brain collection, storage parameters and fatty acids were compared using t-tests for independent samples (two-tailed). The number of comparisons between each fatty acid family (or ratio) was used for the Bonferroni correction. The Kolmogorov-Smirmov test indicated that normality transformations were necessary due to skewed distributions of concentrations (nmol/mg) of 22:4n-6, 20:5n-3 and 22:5n-3. Log-rhythmic transformation improved the distribution and these adjusted variables were used for all analyses. No transformations were required for percentage data. Lastly, the following parameters were used as biochemical indices of the product-substrate relationship for elongation and desaturation in the $n-3$ (ratios of 20:5/18:3, 22:5/20:5, 22:6/22:5, and 22:6/18:3) and n-6 (ratios of 20:3/18:2, 20:4/18:2, 20:4/20:3, and 22:4/20:4) polyunsaturated fatty acid pathways.

\section{Results}

\section{Correlations between Fatty Acids and Brain Collection and Storage Parameters}

No significant differences were observed for brain collection and storage parameters (Table 1). Further, the frequencies of smoking behavior, alcohol use and race were not significantly different between groups (Table 1).

\section{Quantitative Analyses of ACC Polyunsaturated Fatty Acids by Capillary Gas Chromatography}

The mean concentrations of saturated, polyunsaturated, $n-6$ and n-3 fatty acids were significantly lower in the MDD/BPD group compared to the control group (Figure 1). The monounsaturated fatty acid concentration was not significantly different between the two groups. Specifically, the MDD/BPD group had significantly lower levels of phospholipid fatty acids including 14:0, 15:0, 18:2(n-6), 20:2(n-6) and 22:4(n-6), and a "trend-level" difference for 16:0, 20:4(n-6), 22:5(n-3), and 22:6(n-3) after Bonferroni corrections (Table 2). When expressed as a weight percentage, there were no significant differences among saturated, monounsaturated, and polyunsaturated fatty acid families (Table 2).

To characterize the fatty acid elongation and desaturation processes in ACC phospholipid membranes, ratios of product to substrate in different fatty acid families are shown in Table 3. In the $n-6$ fatty acid family, the ratio of 20:3(n-6)/18:2(n-6) was higher ( $\mathrm{p}=0.023$, marginally significant after the Bonferroni correction) in MDD/BPD than in control groups, whereas the ratio of 20:4(n-6)/20:3(n-6) was relatively decreased. In addition, the ratios of 18:0/16:0 and 20:4(n-6)/22:6(n-3) were also elevated marginally after the Bonferroni correction. Group differences were not observed for the other fatty acid families.

\section{Effect of Age on Fatty Acid Concentration}

The relationship between age and the phospholipid fatty acids was also examined. A significant $(\mathrm{r}=-0.6467, \mathrm{p}=0.0231)$ negative correlation between age and 18:3(n-3) contents was demonstrated in MDD/BPD, but not in the control group (Fig. 2). A similar correlation ( $\mathrm{r}=$ $-0.5987, \mathrm{p}=0.0397$ ) between age and 20:5(n-3) contents was also observed in MDD/BPD, but not in the control group (Fig. 2). A marginally significant ( $\mathrm{r}=0.4871, \mathrm{p}=0.0773$ ) positive correlation between age and 22:6(n-3) contents was found in controls, but not in the MDD/ BPD group (data not shown).

Moreover, a significant negative correlation $(\mathrm{r}=-0.8752, \mathrm{p}=0.0002)$ between age and the ratio of 20:4(n-6)/22:6(n-3) was demonstrated in the MDD/BPD group, but not in controls (Fig. 3). 
Marginally significant negative correlations between age and the ratios of total n- 6 to total n-3 fatty acids were found in both controls $(\mathrm{r}=-0.5338, \mathrm{p}=0.0493)$ and the MDD/BPD group ( $\mathrm{r}=$ $-0.5320, \mathrm{p}=0.0750$ ) (Fig. 3). No significant correlations between age and levels of other fatty acids or fatty acid ratios were observed in either control or MDD/BPD groups.

\section{Discussion}

The current study reports significant differences in postmortem brain phospholipid fatty acid concentration in the ACC between adults with and without MDD/BPD. Our findings add to a small, but growing, literature by showing these differences within the ACC, a key anatomical node of the limbic circuit supporting emotional arousal and regulation. Despite these findings a number of limitations are notable. The postmortem approach restricted the sample size and as a result gender and serum fatty acid concentrations were not assessed. Further, dietary intake data were not available. Despite these limitations the current finding supports the notion that the fatty acid concentrations of brain tissue may be an important factor influencing psychiatric symptomatology. Future study of fatty acid content of other brain regions is suggested.

Similar associations demonstrated in animal models also support a relationship between depression and brain fatty acid deficiency. In fact, dietary depletion studies in laboratory rats where the long-chain $\mathrm{n}-3$ fatty acids are removed from the diet lead to reduced monoaminergic function [43-47], as well as behavioral indices of depression on the forced swim test [48]. In animals, dendritic arborization and levels of brain-derived neurotrophic factor (BDNF) are positively associated with intake of the $n-3$ fatty acids [49,50]. Song et al [51] recently reported that EPA and not other n-3 and n-6 fatty acids attenuated depressive-like symptoms brought on by central administration in rats of Interleukin-1, a pro-inflammatory cytokine.

\section{Defective n-6 and n-3 Fatty Acid Families in Postmortem Brain ACC (BA-24) Region from Depressed Individuals}

The ratio of 20:4(n-6)/18:2(n-6) provides a biochemical index of the product- substrate relationship in the $\mathrm{n}-6$ polyenoic pathology. The $\mathrm{n}-6$ pathway consists of a series of desaturation ( $\Delta 6, \Delta 5$, and $\Delta 8$ reaction) and elongations (see Fig. 4). Typically, in human neural membranes, levels of 18:3(n-6), 20:2(n-6), and 22:5(n-6) fatty acids are very minute. 20:4(n-6) is the major metabolic product of 18:2(n-6). Therefore, an increased ratio of 20:3(n-6)/18:2(n-6) associated with relatively decreased ratio of 20:4(n-6)/20:3(n-6), and a normal ratio of 22:4(n-6)/20:4 (n-6) suggest a defect in the $\Delta 5$ desaturation in individuals with MDD/BPD.

22:6(n-3) is formed by a final desaturation at $\Delta 4$. This reaction, however, follows elongation and $\Delta 5$ desaturation in the $n-3$ family (Fig. 4). The ratio of 22:6(n-3)/22:5(n-3) was not significantly different between MDD/BPD and control groups. Therefore, decreases in 22:6 (n-3) may be caused, at least in part, by the diminished formation of 20:5(n-3), which is derived from 20:4(n-3) by the $\Delta 5$ reaction.

Interestingly, evidence from prior studies of mutations in $\Delta 5$ and $\Delta 6$ [52] support this finding. Malabera et al. [52] reported strong associations between polymorphisms in $\triangle 5$ (FADS1) and $\Delta 6$ (FADS2) and levels of arachidonic acid in a large sample of patients with cardiovascular disease. Further, Koletzko et al [53] reported that FADS1 and 2 polymorphisms explained 28\% of the variance in serum arachidonic acid levels. Given that disorders of mood and affect regulation are increasingly associated with inflammation and immunity processes these findings collectively point to the need for future research to address the possibility that certain individuals may differentially require increased n-3 or decreased n-6 dietary intakes. 


\section{Effect of Gender and Cigarette Smoking}

McNamara et al. [23] have recently shown a selective decrease of 22:6(n-3) in the postmortem orbitofrontal cortex (OFC) of MDD patients relative to control subjects. Moreover, such deficits were greater in female MDD patients $(-32 \%)$ than in male MDD patients $(-16 \%)$. In the present study, the gender effect was not evaluated due to the small sample size. However, the approximate $30 \%$ decrease of 22:6(n-3) in postmortem ACC demonstrated in the present study appears to be in the same range of reduction reported by McNamara et al. [23].

Cigarette smoking may affect PUFA levels [51]. Given the high rates of cigarette smoking in patients with psychiatric disorders, the potential confounding effect of smoking on PUFA measures in MDD/BPD patients cannot be ignored [52]. However, the previous study by McNamara et al. [23] indicated that OFC 22:6(n-3) levels were not significantly influenced by cigarette smoking in either MDD patients or controls. In the present study, the effect of cigarette smoking was not assessed due to the small sample size. However, the frequency of cigarette smoking was not significantly different between MDD/BPD patients and the control group. Thus, cigarette smoking alone can not account for the PUFA deficits in postmortem ACC from MDD/BPD patients.

\section{Effect of Age}

Previous work by Carver et al. [42] indicated that age was a highly significant predictor of postmortem cerebral cortex fatty acid levels. Particularly, frontal cortex 22:6(n-3) levels were positively correlated with age among subjects 318 years whereas changes were not prominent among subjects $>18$ years. In the present study, we also demonstrated that the precursors of 22:6(n-3), i.e., 18:3(n-3) and 20:5(n-3), were not correlated significantly with age among controls aged 27 to 77 years (Fig. 2). However, there were significantly negative correlations between the precursors of 22:6(n-3) and age in the MDD/BPD patients (Fig. 2), suggesting that age may be an important confounding factor in regulation of the $\mathrm{n}-3$ fatty acid pathway in $\mathrm{MDD} / \mathrm{BD}$ group.

In response to the reductions of orbitofrontal cortex 22:6(n-3) concentrations, McNamara et al. (23) observed a significantly greater ratio of 20:4(n-6) to 22:6(n-3) in females with MDD. Dietary-induced elevations in the ratio of 20:4(n-6) to 22:6(n-3) in rat prefrontal cortex have been associated with deficits in serotonin and dopamine neurotransmission [43-45,47] as well as increased behavioral indices of depression in the forced swim test [48]. In our study, a significant negative correlation between the ratio of 20:4(n-6) to 22:6(n-3) and age was found in the MDD/BPD group, but not in controls (Fig. 3). Thus, our data provide additional evidence that an increased ratio of 20:4(n-6) to 22:6(n-3) might function as a biomarker for depression.

\section{Brain Morphology and Fatty Acid Intake}

Previously, Conklin and colleagues [36] reported that gray matter volume of the ACC, and other prominent nodes of cortico-limbic circuitry including the hippocampus and amygdala, were positively associated with dietary long-chain n-3 intake in a sample of healthy adults. These associations may mediate previously observed effects of n-3 fatty acids on mood and affect regulation. Unfortunately, few studies have investigated brain morphological correlates of dietary or serum levels of fatty acids in humans. As discussed previously, McNamara et al. reported reduced concentrations of 22:6(n-3), in postmortem orbitofrontal cortex of patients with MDD [23] as well as with BPD [24]. Sublette et al [56] recently examined the association between plasma EPA, DHA and AA and regional cerebral metabolic glucose utilization (rCMRglu) in drug-free depressed adults. DHA and AA correlated positively with rCMRglu in the temporoparietal cortex and negatively in the frontal and anterior cingulate cortices. The differential association between plasma DHA and cerebral metabolic activity in brain areas 
implicated in affect regulation further substantiates the necessity for future research to explore how fatty acid deficiency is involved in the pathophysiology of affective disorders.

While some evidence suggests that fatty acid deficiencies may be related to reduced dietary intake of n-3 fatty acids [6,57], these associations are not fully understood. For example, a number of enzymatic, desaturation and elongation processes are required for longer chain fatty acids to be metabolized from their shorter chain parent precursor fatty acids. It could be the case that in those vulnerable to affective disorders, dysfunctional enzymatic desaturation and elongation activity preclude an optimal level of serum or brain fatty acids. Increased free radical production, secondary to behavioral factors associated with mood disorders such as smoking, alcohol consumption, poor sleep quality, and lack of exercise, could reduce the availability of polyunsaturated fatty acids despite adequate dietary patterns. Lastly, an inability to optimally transfer the longer chain fatty acids across the blood brain barrier, could lead to reduced concentration of brain fatty acids. In the current study, our data suggest a defect or disruption in the activity of the 35 desaturase which may account for the lower levels of DHA seen in the depressed group. In order to better understand the complex relationship that peripheral and central lipids play in psychopathology and also the normative variability in affect, future research should examine the strength of the correlation between central and peripheral lipids.

\section{Acknowledgments}

This study was supported in parts by the Office of Research and Development, Department of Veterans Affairs [Merit Reviews (JKY, SL) and Research Career Scientist Awards (JKY, SL)], NIH T32 HL007560 (SMC, MFM), and the Highland Drive VA Pittsburgh Healthcare System. The funders had no role in study design, data collection and analysis, decision to publish, or preparation of the manuscript. The contents of this article do not represent the views of the Department of Veterans Affairs or the United States Government.

\section{References}

1. Freeman MP, Hibbeln JR, Wisner KL. Omega-3 fatty acids: evidence basis for treatment and future research in psychiatry. J Clin Psychiatry 2006;67:1954-1967. [PubMed: 17194275]

2. Kitajka K, Sinclair AJ, Weisinger RS, Weisinger HS, Mathai M, Jayasooriya AP, Halver JE. Effects of dietary omega-3 polyunsaturated fatty acids on brain gene expression. Proc Natl Acad Sci 2004;101:10931-10936. [PubMed: 15263092]

3. Hulbert AJ, Turner N, Storlien LH, Else PL. Dietary fats and membrane function: implications for metabolism and disease. Biol Rev 2005;80:155-169. [PubMed: 15727042]

4. Tashiro T, Yamamori H, Takagi K, Hayashi N, Furukawa K, Nakajima N. N-3 Versus N-6 polyunsaturated fatty acids in critical illness. Nutrition 1998;14:551-553. [PubMed: 9646301]

5. Young G, Conquer J. Omega-3 fatty acids and neuropsychiatric disorders. Reprod Nutr Dev 2005;45:128. [PubMed: 15865053]

6. Hibbeln JR. Fish consumption and major depression. Lancet 1998;351:1213. [PubMed: 9643729]

7. Hibbeln JR. Seafood consumption, the DHA content of mothers milk and prevalence rates of postpartum depression: a cross-national, ecological analysis. J Affect Disord 2002;69:15-29. [PubMed: 12103448]

8. Tanskanen A, Hibblen JR, Tuomilehto J, Uutela A, Haukala A, Viinamaki H, Lehtonen J. Fish consumption and depressive symptoms in the general population in Finland. Psychiatric Services 2001;52:529-531. [PubMed: 11274502]

9. Peet M, Murphy B, Shay J, Horrobin DF. Depletion of omega-3 fatty acid levels in red blood cell membranes of depressive patients. Biol Psychiatry 1998;43:315-319. [PubMed: 9513745]

10. Maes M, Smith R, Christophe A, Cosyns P, Desnyder R, Meltzer HY. Fatty acid composition in major depression: decreased $\omega 3$ fractions in cholesteryl esters and increased c20:4 $66 / \mathrm{c} 20: 5 \omega 3$ ratio in cholesteryl esters and phospholipids. J Affect Disord 1996;38:35-46. [PubMed: 8735157]

11. Chui CC, Huang SY, Su KP, Lu ML, Huang MC, Chen CC, Shen WW. Polyunsaturated fatty acid deficit in patients with bipolar mania. Eur Neurophyschopharma 2003;13:99-103. 
12. Stoll AL, Severus WE, Freeman MP. Omega-3 fatty acids in bipolar disorder: a preliminary double blind, placebo-controlled trial. Arch Gen Psychiatry 1999;56:407-412. [PubMed: 10232294]

13. Zanarini MC, Frakenburg FR. Omega-3 fatty acid treatment of women with borderline personality disorder: a double-blind, placebo-controlled pilot study. Am J Psychiatry 2003;160:167-169. [PubMed: 12505817]

14. Frasure-Smith N, Lesperance F, Julien P. Major depression is associated with lower omega-3 fatty acids levels in patients with recent acute coronary syndromes. Biol Psychiatry 2004;55:891-896. [PubMed: 15110732]

15. Nemets B, Stahl Z, Belmaker RH. Addition of omega-3 fatty acid to maintenance medication treatment for recurrent unipolar depressive disorder. Am J Psychiatry 2002;159:477-479. [PubMed: 11870016]

16. Peet M, Horrobin DF. A dose-ranging study of the effects of ethyl-eicopentaenoic acid in patients with on-going depression in spite of apparently adequate Treatment with standard drugs. Arch Gen Psychiatry 2001;59:913-919. [PubMed: 12365878]

17. Su KP, Huang SY, Chiu CC. Omega-3 fatty acids in major depressive disorder: a preliminary doubleblind placebo controlled trial. Eur Neuropsychopharm 2003;13:267-271.

18. Marangell LB, Martinez JM, Zboyan HA, et al. A double-blind, placebo-controlled study of the omega-3 fatty acid docosahexaenoic acid in the treatment of major depression. Am J Psychiatry 2003;160:996-998. [PubMed: 12727707]

19. Ness AR, Gallacher JE, Bennett PD, Gunnell DJ, Rogers PJ, Kessler D, Burr ML. Advice to eat fish and mood: a randomized controlled trial of men with angina. Nutritional Neuroscience 2003;6:6365. [PubMed: 12608739]

20. Rogers PJ, Appleton KM, Kesler D, Peters TJ, Gunnell D, Hayward RC, Heatherley SV, Christian LM, McNaughton SA, Ness AR. No effect of n-3 long-chain Ppolyunsaturated fatty acids (EPA and DHA) supplementation on depressed mood and cognitive function: a randomized controlled trial. Brit J Nutrition 2008;99:421-431. [PubMed: 17956647]

21. Conklin SM, Harris JI, Manuck SB, Yao JK, Hibbeln JR, Muldoon MF. Serum 3-3 fatty acids are associated with variation in mood, personality and behavior in hypercholesterolemic community volunteers. Psychiatry Res 2007;152:1-10. [PubMed: 17383013]

22. Lalovic A, Levy E, Canetti L, Sequeira A, Montoudis A, Turecki G. Fatty acid composition in postmortem brains of people who completed suicide. J Psychiatry and Neuroscience 2007;32:363370.

23. McNamara RK, Hahn CH, Jandacek R, Rider T, Tso P, Stanford KE, Richtand NM. Selective deficits in the omega-3 fatty acid docosahexaenoic acid in the postmortem orbitofrontal cortex of patients with major depressive disorder. Biol Psychiatry 2007;62:17-24. [PubMed: 17188654]

24. McNamara RK, Jandacek R, Rider T, Tso P, Stanford KE, Hahn CG, Richtand NM. Deficits in docosahexaenoic acid and associated elevations in the metabolism of arachidonic acid and saturated fatty acids in the postmortem orbitofrontal cortex of patients with bipolar disorder. Psychiatry Res 2008;160:285-299. [PubMed: 18715653]

25. Drevets WC. Functional anatomical abnormalities in limbic and prefrontal cortical structures in major depression. Prog Brain Res 2000:413-431. [PubMed: 11105660]

26. Van Veen V, Cohen JD, Botvinick MM, Stenger V, Carter CS. Anterior cingulate cortex, conflict monitoring and levels of processing. NeuroImage 2001;14:1302-1308. [PubMed: 11707086]

27. MacDonald AW, Cohen JD, Stenger VA, Carter CS. Dissociating the role of the dorsolateral prefrontal and anterior cingulate cortex in cognitive control. Science 2000;288:1835-1838. [PubMed: 10846167]

28. Drevets WC. Prefrontal cortical-amygdalar metabolism in major depression. Ann NY Academy Sci 1999;877:614-637.

29. Breiter HC, Rauch SL, Kwong KK, Baker JR, Weisskoff RM, Kennedy DN, Kendrick AD, Davis TL, Jiang A, Cohen MS, Stern CE, Belliveau JW, Baer L, O'Sullivan RL, Savage CR, Jenike MA, Rosen BR. Functional magnetic resonance imaging of symptom provocation in obsessivecompulsive disorder. Arch Gen Psychiatry 1996;53:595-606. [PubMed: 8660126] 
30. Amir N, Klumpp H, Elias J, Bedwell JS, Yanasak N, Miller LS. Increased activation of the anterior cingulate cortex during processing of disgust faces in individuals with social phobia. Biol Psychiatry 2005;57:975-981. [PubMed: 15860337]

31. Binder DK, Iskandar BJ. Modern neurosurgery for psychiatric disorders. Neurosurgery 2000;47:921. [PubMed: 10917342]

32. Gianaros PJ, Derbyshire SWG, May C, Siegle GJ, Gamalo MA, Jennings JR. Anterior cingulate activity correlates with blood pressure during stress. Psychophysiology 2005;42:627-635. [PubMed: 16364058]

33. Mayberg HS. Limbic-cortical dysregulation: a proposed model of depression. J Neuropsychiatry Clin Neurosci 1997;9:471-481. [PubMed: 9276848]

34. Pizzagalli D, Pascual-Marqui RD, Nitschke JB, Oakes TR, Larson CL, Abercromnie HC, Schaefew SM, Koger JV, Benca RM, Davidson R. Anterior cingulate activity as a predictor of degree of treatment response in major depression: evidence from brain electrical tomography analysis. Am J Psychiatry 2001;158:405-415. [PubMed: 11229981]

35. Parker G, Gibson NA, Brotchie H, Heruc G, Rees AM, Hadzi-Pavlovic D. Omega-3 fatty acids and mood disorders. Am J Psychiatry 2006;163:969-978. [PubMed: 16741195]

36. Conklin SM, Gianaros PJ, Brown SM, Yao JK, Hariri AR, Manuck SB, Muldoon MF. Long-chain omega-3 fatty acid intake is associated positively with corticolimbic gray matter volume in healthy adults. Neurosci Lett 2007;421:209-212. [PubMed: 17574755]

37. Leonard S, Logel J, Luthman D, Casanova M, Kirch D, Freedman R. Biological stability of MRNA isolated from human postmortem brain collection. Biol Psychiatry 1993;33:456-466. [PubMed: 8098224]

38. Hardy JA, Wester P, Winblad B, Gezelius C, Bring G, Eriksson A. The patients dying after long terminal phase have acidotic brains; implications for biochemical measurements on autopsy tissue. J Neural Transm 1985;61:253-264. [PubMed: 3989524]

39. Yao JK, van Kammen DP, Welker JA. Red blood cell membrane dynamics in schizophrenia. II. fatty acid composition. Schizophr Res 1994;13:217-226. [PubMed: 7841134]

40. Yao JK, Leonard S, Reddy R. Membrane phospholipid abnormalities in postmortem brains from schizophrenic patients. Schizophr Res 2000;42:7-17. [PubMed: 10706981]

41. Elliott KAC, Jasper H. Measurement of experimentally induced brain swelling and shrinkage. Am J Physiology 1949;157:122-129.

42. Carver JD, Benford VJ, Han B, Cantor AB. The relationship between age and the fatty acid composition of cerebral cortex and erythrocytes in human subjects. Brain Res Bull 2001;56:79-85. [PubMed: 11704343]

43. Delion S, Chalon S, Guilloteau D, Besnard JC, Durand G. Alpha-linolenic acid dietary deficiency alters age-related changes of dopaminergic and serotoninergic neurotransmission in the rat frontal cortex. J Neurochem 1996;66:1582-1591. [PubMed: 8627314]

44. De la Pressa Owens S, Innis SM. Docosahexaenoic and arachidonic Acid prevent a decrease in dopoaminergic and serotonergic neurotransmitters in frontal cortex caused by linoleic and alphalinoleic acid deficient diet in formula-fed piglets. J Nutrition 1999;129:2088-2093. [PubMed: 10539789]

45. Kodas E, Vancassel S, Lejeune B, Guilloteau D, Chalon S. Reversibility of n- 3 fatty acid deficiencyinduced changes in dopaminergic neurotransmission in rats: critical role of developmental stage. J Lipid Res 2002;43:1209-1219. [PubMed: 12177165]

46. McNamara RK, Ostrander M, Abplanalp W, Richtand NM, Benoit SC, Clegg DJ. Modulation of phosphoinositide-protein kinase $\mathrm{C}$ signal transduction by omega-3 fatty acids: implications for the pathophysiology and treatment of recurrent neuropsychiatric illness. Prostaglandins Leukot Essent Fatty Acids 2006;75:237-257. [PubMed: 16935483]

47. Zimmer L, Vancassel S, Cantagrel S, Breton P, Delamanche S, Guilloteau D, Durand G, Chalon S. The dopamine mesocorticolimbic pathway is affected by deficiency in $n-3$ polyunsaturated fatty acids. Am J Clin Nutr 2002;75:662-667. [PubMed: 11916751]

48. DeMar JC Jr, Ma K, Bell JM, Igarashi M, Greenstein D, Rapoport SI. One generation of n-3 polyunsaturated fatty acid deprivation increases depression and aggression test scores in rats. J Lipid Res 2006;47:172-180. [PubMed: 16210728] 
49. Calderon F, Kim HY. Docosahexaenoic acid promotes neurite growth in hippocampal neurons. J Neurochem 2004;90:979-988. [PubMed: 15287904]

50. Kawakita E, Hashimoto M, Shido O. Docosahexaenoic acid promotes neurogenesis in vitro and in vivo. Neuroscience 2006;139:991-997. [PubMed: 16527422]

51. Song C, Manku MS, Horrobin DF. Long-chain polyunsaturated fatty acids modulate interleukin-1 beta-induced changes in behavior, monoaminergic neurotransmitters, and brain inflammation in rats. J Nutr 2008;138:954-963. [PubMed: 18424607]

52. Malerba G, Schaeffer 1, Xumerle L, Klopp N, Trabetti E, Biscuola M, Cavallari U, Galavotti R, Martinelli N, Guarini P, Girelli D, Olivieri O, Corrocher R, Heinrich J, Pignatti PF, Illig T. SNPs of the FADS gene clusters are associated with polyunsaturated fatty acids in a cohort of patients with cardiovascular disease. Lipids 2008;43:289-299. [PubMed: 18320251]

53. Koletzko B, Demmelmair H, Schaeffer L, Illig T, Heinrich J. Genetically determined variation in polyunsaturated fatty acid metabolism may result in different dietary requirements. Nestle Nutr Workshop Ser Pediatr Program 2008;62:35-49.

54. Pawlosky R, Hibbeln J, Wegher B, Sebring N, Salem N Jr. The effects of cigarette smoking on the metabolism of essential fatty acids. Lipids 1999;34(Suppl):S287. [PubMed: 10419179]

55. Hibbeln JR, Makino KK, Martin CE, Dickerson F, Boronow J, Fenton WS. Smoking, gender, and dietary influences on erythrocyte essential fatty acid composition among patients with schizophrenia or schizoaffective disorder. Biol Psychiatry 2003;53:431-441. [PubMed: 12614996]

56. Sublette M, Milak MS, Hibbeln JR, Freed PJ, Oquendo MA, Malone KM, Parsey RV, Mann JJ. Plasma polyunsaturated fatty acids and regional cerebral glucose metabolism in major depression. Prostaglandins Leukot Essent Fatty Acids 2009;80:57-64. [PubMed: 19128951]

57. Edwards R, Peet M, Shay J, Horrobin DF. Omega-3 polyunsaturated fatty acid levels in the diet and in red blood cell membranes of depressed patients. J Affect Disord 1998;48:149-155. [PubMed: 9543204] 


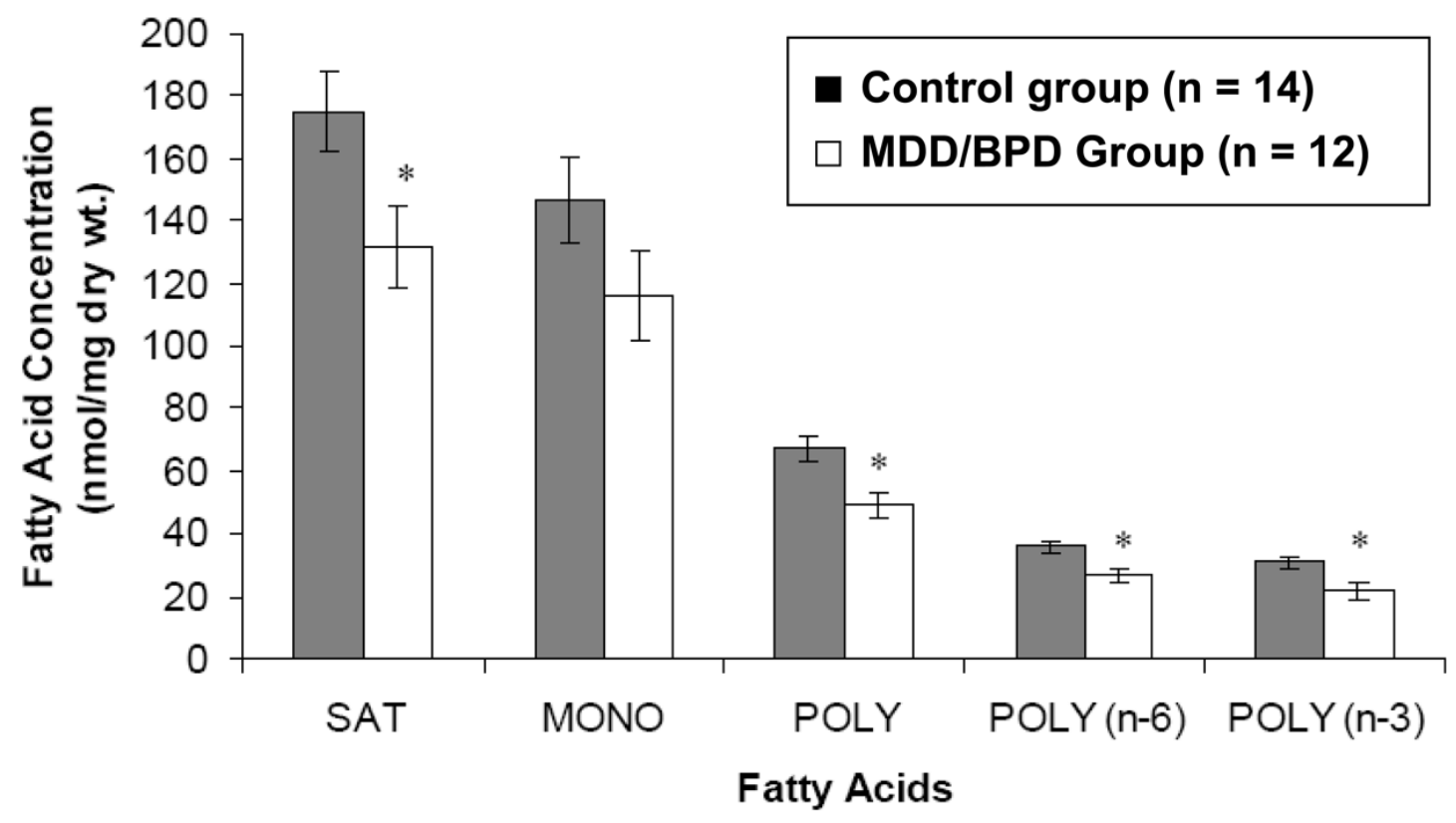

Figure 1.

Comparisons of saturated (SAT), monounsaturated (MONO) and polyunsaturated (POLY) fatty acids in postmortem mid anterior cingulate cortex between the control and major depressive disorder/bipolar disorder (MDD/BPD) groups. $(*, p<0.05)$ 

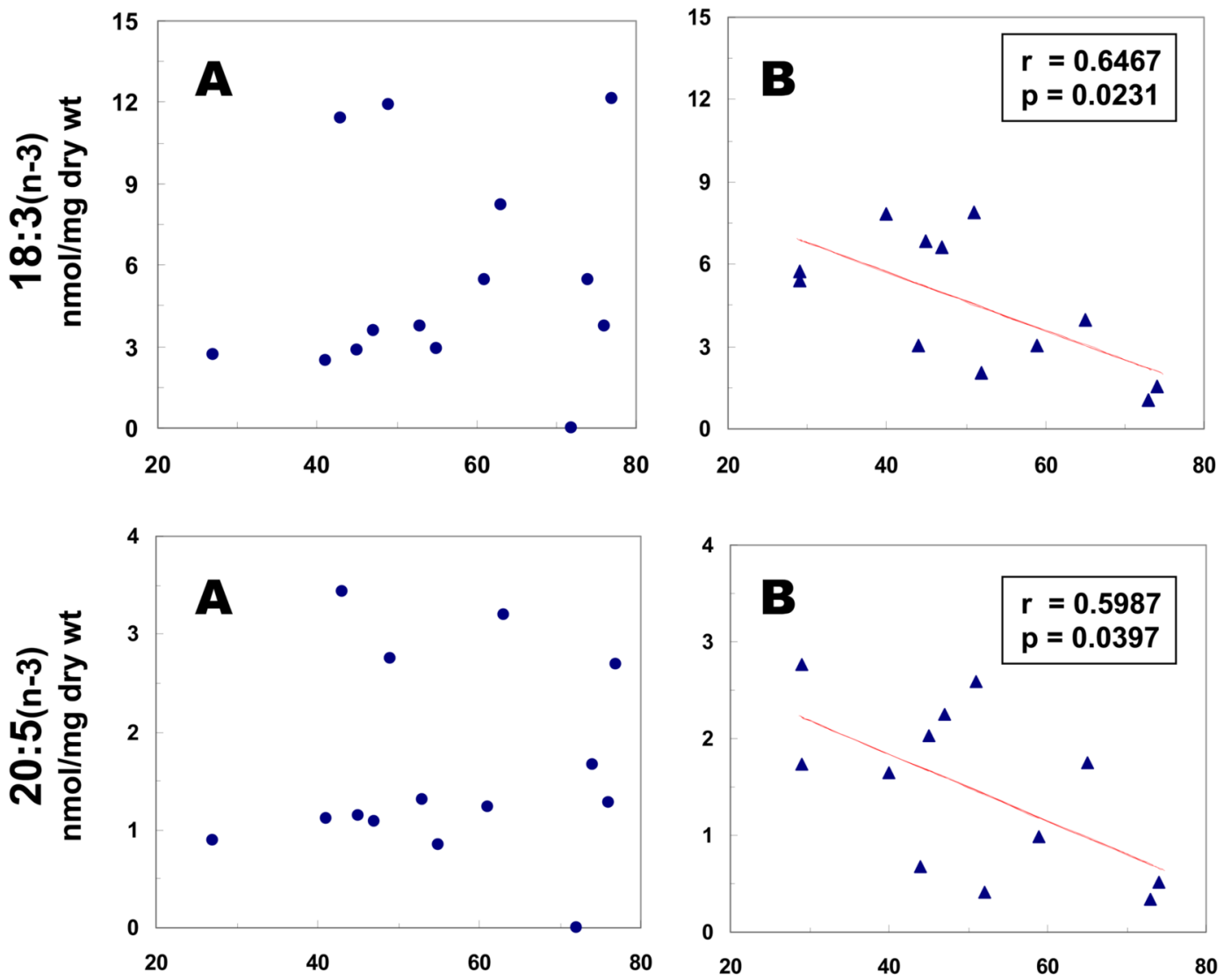

Age, years

Figure 2.

Linear regression analyses between age at death and selective n-3 fatty acid concentrations in postmortem mid anterior cingulate cortex from controls (A) and MDD/BPD groups (B). 

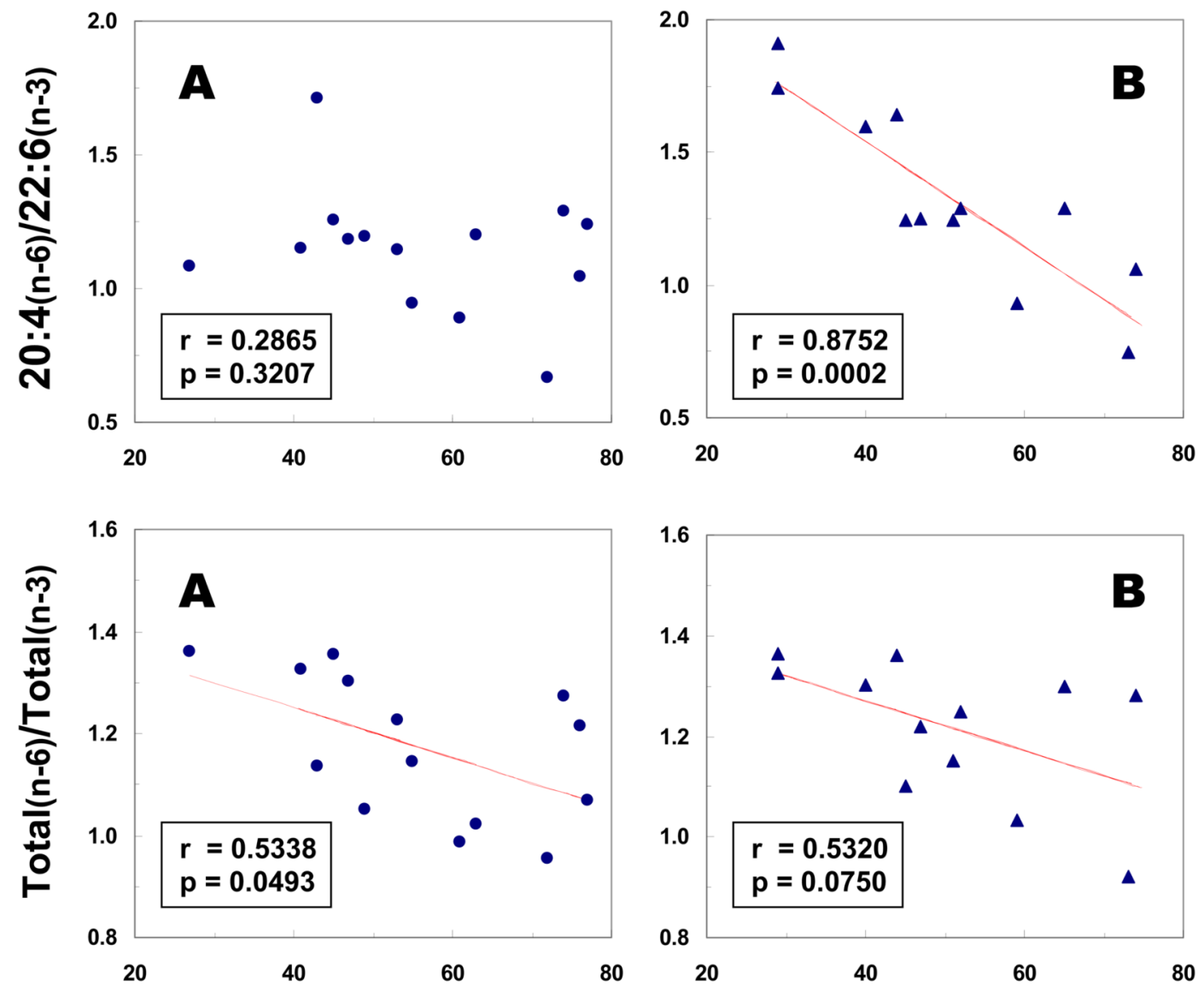

Age, years

Figure 3.

Linear regression analyses between age at death and selective n-6 to n-3 fatty acid ratios in postmortem mid anterior cingulate cortex from controls (A) and MDD/BPD groups (B). 

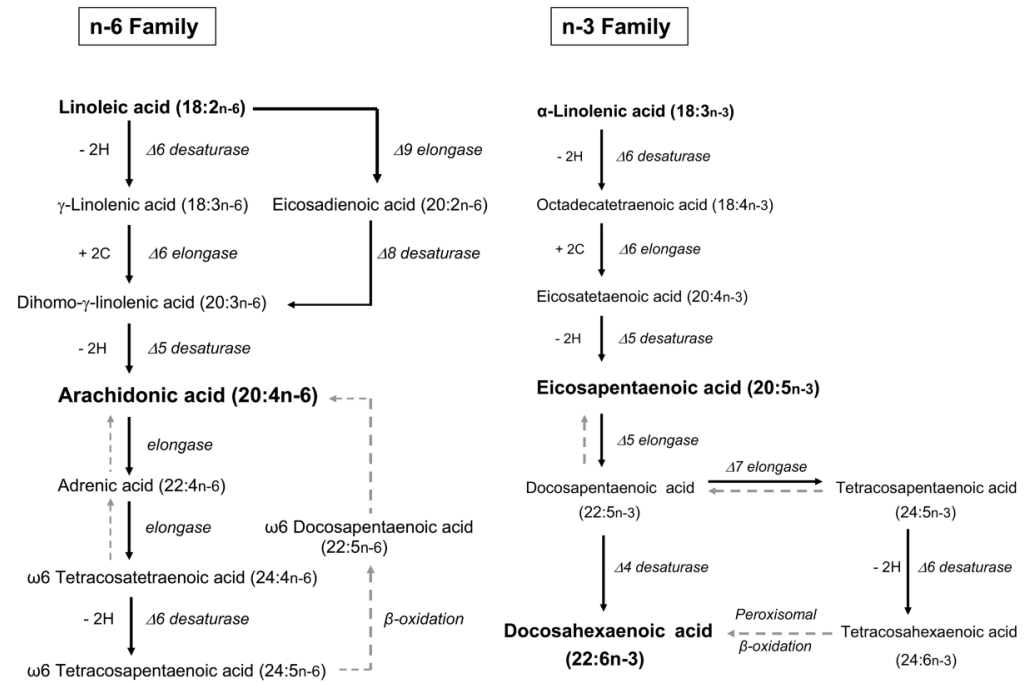

Figure 4.

The common pathways for biosynthesis of $n-6$ and $n-3$ polyunsaturated fatty acids. The retroconversion is shown in gray, dashed arrows. 
Table 1

Brain collection and storage parameters

\begin{tabular}{|l|c|c|c|}
\hline Parameters & Control & MDD/BPD & P values \\
\hline Age (years, range) & $53.4 \pm 14.5(27-77)$ & $50.7 \pm 15.0(29-74)$ & 0.522 \\
\hline Sex (M/F) & $8 / 6$ & $8 / 4$ & 0.618 \\
\hline Race (C/AA/H) & $13 / 0 / 1$ & $10 / 1 / 1$ & 0.537 \\
\hline Smoking (S/FS/NS) & $3 / 5 / 6$ & $6 / 4 / 2$ & 0.226 \\
\hline Alcohol use (Y/N/U) & $4 / 7 / 3$ & $8 / 3 / 1$ & 0.149 \\
\hline Cause of death & & & \\
\hline Suicide & 0 & 4 & \\
\hline Accident & 2 & 1 & \\
\hline Cardiac related & 2 & 3 & \\
\hline Respiratory related & 7 & 3 & \\
\hline Other & 3 & 1 & \\
\hline Postmortem brain & & & \\
\hline PMI interval (hrs) & $14.4 \pm 7.8$ & $14.4 \pm 6.5$ & 0.984 \\
\hline Brain weight (grams) & $1311.1 \pm 148.9$ & $1391.7 \pm 157.2$ & 0.192 \\
\hline Storage time (months) & $32.1 \pm 12.7$ & $40.7 \pm 19.0$ & 0.186 \\
\hline
\end{tabular}

Each value represents the mean and standard deviation based on the number of examined brain samples (BA24). MDD/BPD, major depressive disorder and bipolar disorder; $\mathrm{C}=$ Caucasian; $\mathrm{AA}=$ African American; $\mathrm{H}=$ Hispanic; $\mathrm{S}=$ smoker, $\mathrm{FS}=$ former smoker, $\mathrm{NS}=$ Never Smoked; $\mathrm{Y}=$ yes; $\mathrm{N}=$ no; $\mathrm{U}=$ unknown; $\mathrm{PMI}=$ postmortem interval 
政

峦

\begin{tabular}{|c|c|c|c|c|c|c|c|c|c|c|c|c|c|c|c|c|c|c|c|c|c|c|c|c|c|c|}
\hline $0^{\circ}$ & & $\begin{array}{l}\stackrel{0}{0} \\
0 \\
+1 \\
o \\
\stackrel{-}{-}\end{array}$ & 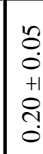 & $\begin{array}{l}q \\
q \\
i \\
+1 \\
i \\
\sim \\
\dot{d} \\
\dot{d}\end{array}$ & 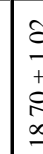 & $\begin{array}{l}\text { oे } \\
0 \\
+1 \\
\text { के } \\
\vdots\end{array}$ & & $\begin{array}{l}0 \\
\stackrel{0}{0} \\
+1 \\
\infty \\
\infty \\
0 \\
0\end{array}$ & 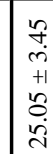 & $\begin{array}{l}3 \\
0 \\
0 \\
+1 \\
0 \\
\text { in }\end{array}$ & $\begin{array}{l}0 \\
0 \\
+ \\
i \\
0\end{array}$ & $\begin{array}{l}8 \\
i \\
0 \\
+1 \\
2 \\
2\end{array}$ & & & & $\begin{array}{l}0 \\
0 \\
+1 \\
+1 \\
\hat{0} \\
0\end{array}$ & $\begin{array}{l}8 \\
0 \\
0 \\
+1 \\
n \\
0 \\
0\end{array}$ & $\mid \begin{array}{l}0 \\
0 \\
0 \\
+1 \\
0 \\
0 \\
0\end{array}$ & $\mid \begin{array}{l}\hat{\sigma} \\
0 \\
+1 \\
+1 \\
0 \\
0 \\
0\end{array}$ & $\begin{array}{l}q \\
0 \\
0 \\
+1 \\
n \\
\end{array}$ & & $\begin{array}{l}n \\
n \\
+1 \\
+1 \\
n \\
n\end{array}$ & \begin{tabular}{l}
0 \\
0 \\
0 \\
+1 \\
\multirow{J}{0}{} \\
0
\end{tabular} & $\begin{array}{l}\infty \\
0 \\
0 \\
+1 \\
\text { ते }\end{array}$ & 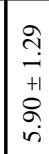 & 8 \\
\hline 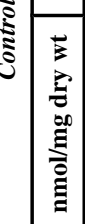 & & $\begin{array}{l}+\hat{\sigma} \\
\hat{0} \\
+1 \\
+1 \\
o \\
\dot{\gamma}\end{array}$ & 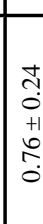 & $\begin{array}{l}\text { in } \\
\infty \\
\text { i } \\
+1 \\
= \\
= \\
0\end{array}$ & 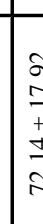 & 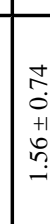 & & $\begin{array}{l}\text { ô } \\
0 \\
+1 \\
\text { mे } \\
\text { mे }\end{array}$ & $\begin{array}{l}n \\
\sigma \\
\infty \\
m \\
+1 \\
\sim \\
2 \\
\alpha\end{array}$ & 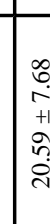 & {$\left[\begin{array}{l}0 \\
+ \\
+ \\
\infty \\
-\end{array}\right.$} & $\begin{array}{l}\alpha \\
\text { d } \\
\text { r } \\
+ \\
\text { gे } \\
\text { o }\end{array}$ & & & & 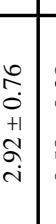 & \begin{tabular}{l}
$\infty$ \\
\multirow{1}{1}{} \\
+1 \\
$\infty$ \\
0 \\
0
\end{tabular} & 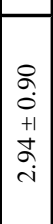 & 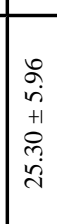 & 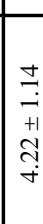 & & 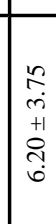 & $\begin{array}{l}2 \\
\infty \\
0 \\
+1 \\
0 \\
\stackrel{1}{-}\end{array}$ & 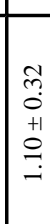 & 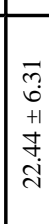 & $\begin{array}{l}\exists \\
+1 \\
+1 \\
\infty \\
\infty\end{array}$ \\
\hline 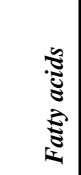 & 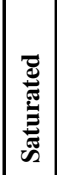 & $\stackrel{\mathscr{\ddot { \pm }}}{ }$ & 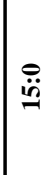 & ثِ & $\dot{\dot{\alpha}}$ & $\stackrel{\ddot{\bar{N}}}{ }$ & $\begin{array}{l}\text { 巳̆ } \\
\bar{\Xi}\end{array}$ & 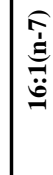 & & 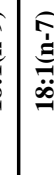 & 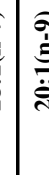 & 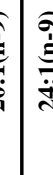 & 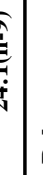 & 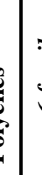 & 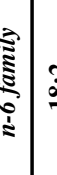 & $\stackrel{\mathscr{\otimes}}{\mathscr{\otimes}}$ & ஸ̊ำ & $\stackrel{m}{\tilde{N}}$ & 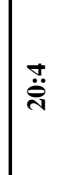 & 華 & 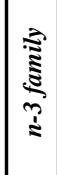 & $\stackrel{\mathscr{\otimes}}{\otimes}$ & 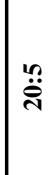 & 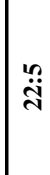 & 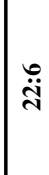 & పूँ \\
\hline
\end{tabular}




\section{Table 3}

Comparisons of fatty acid elongation and desaturation in brain anterior cingulate cortex (BA 24) region between patients with MDD/BPD and control subjects.

\begin{tabular}{|c|c|c|c|}
\hline Ratio & Control & MDD/BPD & $\mathbf{P}^{*}$ \\
\hline \multicolumn{4}{|l|}{ n family } \\
\hline $16: 0 / 14: 0$ & $23.59 \pm 4.11^{\dagger}$ & $21.93 \pm 3.45$ & 0.272 \\
\hline $18: 0 / 16: 0$ & $0.76 \pm 0.07$ & $0.84 \pm 0.11$ & 0.037 \\
\hline \multicolumn{4}{|l|}{ n-3 family } \\
\hline $20: 5 / 18: 3$ & $0.31 \pm 0.07$ & $0.32 \pm 0.09$ & 0.760 \\
\hline $22: 5 / 20: 5$ & $0.73 \pm 0.31$ & $0.73 \pm 0.59$ & 0.983 \\
\hline $22: 6 / 22: 5$ & $21.32 \pm 6.22$ & $19.90 \pm 5.45$ & 0.540 \\
\hline $22: 6 / 18: 3$ & $4.83 \pm 2.73$ & $3.65 \pm 2.63$ & 0.288 \\
\hline \multicolumn{4}{|l|}{ n-6 family } \\
\hline $20: 3 / 18: 2$ & $1.03 \pm 0.27$ & $1.49 \pm 0.58$ & 0.023 \\
\hline $20: 4 / 20: 3$ & $9.02 \pm 2.19$ & $7.96 \pm 1.49$ & 0.160 \\
\hline $20: 4 / 18: 2$ & $9.18 \pm 3.15$ & $11.39 \pm 3.56$ & 0.111 \\
\hline $22: 4 / 20: 4$ & $0.17 \pm 0.05$ & $0.16 \pm 0.04$ & 0.473 \\
\hline \multicolumn{4}{|l|}{ n-7 family } \\
\hline $18: 1 / 16: 1$ & $6.04 \pm 1.12$ & $6.58 \pm 0.96$ & 0.198 \\
\hline \multicolumn{4}{|l|}{ n-9 family } \\
\hline $18: 1 / 18: 0$ & $1.35 \pm 0.24$ & $1.36 \pm 0.22$ & 0.899 \\
\hline $20: 1 / 18: 1$ & $0.023 \pm 0.004$ & $0.023 \pm 0.004$ & 0.887 \\
\hline \multicolumn{4}{|l|}{$n-6 / n-3$ families } \\
\hline $18: 2 n-6 / 18: 3 n-3$ & $0.64 \pm 0.36$ & $0.41 \pm 0.20$ & 0.058 \\
\hline $20: 4 n-6 / 20: 5 n-3$ & $16.98 \pm 6.96$ & $14.58 \pm 6.52$ & 0.384 \\
\hline $20: 4 n-6 / 22: 6 n-3$ & $1.16 \pm 0.21$ & $1.38 \pm 0.30$ & 0.048 \\
\hline total $n-6 /$ total $n-3$ & $1.17 \pm 0.14$ & $1.25 \pm 0.11$ & 0.154 \\
\hline
\end{tabular}

Statistical analysis ( $p$ values) was made between control and MDD/BPD (major depressive disorder and bipolar disorder) groups using a two-tailed unpaired $t$-test.

${ }^{\dagger}$ Each ratio represents mean and standard deviation. 